\title{
HS-SPME AS AN EFFICIENT TOOL FOR DISCRIMINATING CHEMOTYPES OF Lippia alba (Mill.) N. E. Brown"
}

\author{
Aiêrta C. C. da Silva ${ }^{a}$, Francisco G. Barbosa ${ }^{a}$, , Jair Mafezolia, Maria da C. F. de Oliveira ${ }^{a}$ e Terezinha F. de Oliveirab \\ a'Departamento de Química Orgânica e Inorgânica, Universidade Federal do Ceará, 60455-760 Fortaleza - CE, Brasil

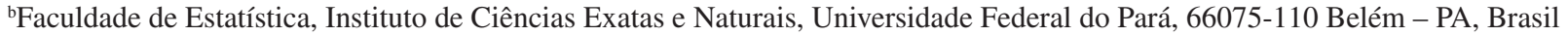

Recebido em 15/04/2016; aceito em 15/07/2016; publicado na web em 26/08/2016

\begin{abstract}
HS-SPME AS AN EFFICIENT TOOL FOR DISCRIMINATING CHEMOTYPES OF Lippia alba (Mill.) N. E. Brown. Lippia alba (Mill.) N. E. Brown (Verbenaceae) is a medicinal plant for which several biological activities are reported, such as sedative, anxiolytic, anti-ulcer, antifungal, antimicrobial, antioxidant, antispasmodic, anti-nociceptive and anti-inflammatory. It is characterized by the production of essential oils which have been used to classify the plant in different chemotypes. In the Northeast region of Brazil, the presence of three chemotypes are reported: myrcene-citral (chemotype I), limonene-citral (chemotype II) and carvone-limonene (chemotype III). In this work, headspace-solid phase microextraction (HS-SPME) was used on the analysis of the volatile organic compounds (VOCs) of three chemotypes of L. alba from the Northeast region of Brazil, and compared to the essential oils of the plants extracted by hydrodistillation. Volatile compounds from each chemotype were more effectively differentiated when extracted by HS-SPME than by hydrodistillation.
\end{abstract}

Keywords: Lippia alba; chemotypes; essential oils; HS-SPME.

\section{INTRODUCTION}

Lippia alba (Mill.) N. E. Brown (Verbenaceae) is a medicinal plant native from South and Central America, but also found in India and Australia. ${ }^{1}$ In Brazil, the widespread plant is known as "falsamelissa" or "erva-cidreira", and it is popularly used for treating hypertension, cough, nausea and digestive problems. ${ }^{1-4}$ Additionally, L. alba displays sedative, anxiolytic, antiulcer, antifungal, antimicrobial, antioxidant, antispasmodic, anti-nociceptive and antiinflammatory activities. ${ }^{5-10}$ The ethnopharmacological importance of L. alba was recognized in Europe by its introduction in the French Pharmacopeia and by its approval by the French Drug Agency (AFSSaPS). It is worth mentioning that L. alba and Senna alata (L.) Roxb. (Fabaceae) were the first non-European plants approved by the French agency. ${ }^{1}$

Different classes of secondary metabolites such as flavonoids, biflavonoids, tannins, iridoids, glycosides of phenylethanoid and saponins triterpene are reported in the non-volatile chemical composition of $L$. alba. ${ }^{11,12}$ The species is also notable for essential oil production and the monoterpenes citral (neral and geranial), linalool, limonene, carvone, camphor, 1,8-cineole, tangetenona, $\gamma$-terpineno and estragole are reported as major constituents. ${ }^{1,13}$

Qualitative and quantitative variations in the chemical composition of the essential oil, besides genotype, geographical origin, soil and weather factors and techniques of extraction, are used to discriminate chemotypes of L. alba.${ }^{14-16}$ According to Hennebelle et al.,${ }^{13}$ besides the existence of different morphotypes of $L$. alba, the plant also has seven chemotypes which are characterized by different major constituents in their essential oils. ${ }^{13}$ Later on, Mesa-Arango et al. ${ }^{10}$ suggested the existence of at least twelve chemotypes of this species. These authors reported the citral and carvone chemotypes for the plant collected in Colombia, besides the promising antifungal activity of its essential oil. ${ }^{10}$ The investigation of the essential oil composition of $L$. alba collected in Uruguay revealed the monoterpenes canfora

*e-mail: fgerhar@gmail.com

\#This paper is part of the PubliSBQ Special Issue in honor of the late Prof. Angelo da Cunha Pinto. and 1,8-cineole as major constituents, while the essential oil of the same species collected in Cuba has carvone and $\beta$-guaiene as major compounds. ${ }^{17,18}$

Studies on the chemical composition of the essential oil of L. alba collected in different regions of Brazil also revealed the existence of different chemotypes of the plant. Three chemotypes [A (1,8-cineole, limonene, carvone and sabinene), B (limonene, carvone and mircene) and $C$ (citral, germacrene-D and $\beta$-cariophylene)] were identified for the species collected in the Amazon region. In the South region, the essential oil of $L$. alba collected in different periods of the year produced linalool and 1,8-cineole as major compounds. Citral and $\beta$-cariophylene were the major constituents in the essential oil investigation of the plant from the southeast region. ${ }^{19-21}$ In the Northeast region of Brazil, the existence of the mircene-citral (chemopype I), limonene-citral (chemotype II) and carvone-limonene (chemotype III) chemotypes is reported. ${ }^{1}$ In addition to these, the study on the chemical composition of the essential oils from sixteen specimens of $L$. alba from different regions of Brazil led to the identification of seven chemotypes of the plant: citral-limonene, citral-mircene, limonene-carvone, citral, linalool, mircene and linalool-limonene. ${ }^{22}$

Although most discriminations of vegetal chemotypes involve studies on the volatile organic compounds (VOCs) extracted by hydrodistillation, the solid phase microextraction (SPME) has been proved to be a complementary tool for this kind of investigation. Sabino et al. used SPME for discriminating three chemotypes of L. graveolens, ${ }^{23}$ while Schossler et al. compared the volatile composition of Baccharis punctulata, B. dracunculifolia and Eupatorium laevigatum by hydrodistillation and SPME. ${ }^{24}$ In the studies involving SPME, the volatile compounds are mostly extracted by headspace (HS). It is worth mentioning that no previous work involving the use of HS-SPME for discriminating L. alba chemotypes was found in the literature.

Thus, herein we report the use of HS-SPME for discriminating three chemotypes of $L$. alba from Northeast region of Brazil collected at the Horto of Medicinal Plants of Universidade Federal do Ceará, and compare this analytical tool with the hydrodistillation method. 


\section{EXPERIMENTAL}

\section{Plant material}

Leaves from three chemotypes of $L$. alba were collected at the Horto de Plantas Medicinais Francisco José de Abreu Matos, Universidade Federal do Ceará (UFC), in January 2014. All specimens were cultivated under the same conditions and the samples were always collected at 9 a.m. Voucher specimens of the three chemotypes are deposited at Herbário Prisco Bezerra (EAC) of UFC under the following register numbers 24.151 (chemotype I), 24.150 (chemotype II) and 24.149 (chemotype III)

\section{Essential oils extraction}

The essential oil of each chemotype of L. alba was extracted for $2 \mathrm{~h}$ by hydrodistillation ${ }^{25}$ from $100 \mathrm{~g}$ of fresh leaves in a $2 \mathrm{~L}$ round flask containing the plant and $1 \mathrm{~L}$ of distilled water. The extractions were performed in triplicate. The essential oils, collected using a modified Clevenger trap, were dried with anhydrous $\mathrm{Na}_{2} \mathrm{SO}_{4}$, filtered and stored in amber vials under $\mathrm{N}_{2}$ atmosphere. The yields were: $0.07 \% \pm 0.02$ (chemotype I), $0.52 \% \pm 0.15$ (chemotype II) and $0.35 \%$ \pm 0.19 (chemotype III).

\section{Headspace-Solid phase microextraction (HS-SPME)}

The VOCs of each chemotype of $L$. alba were extracted in triplicate by HS-SPME using a $65 \mu \mathrm{m}$ dimethylpolysiloxanedivinylbenzene - PDMS/DVB (Sigma-Aldrich ${ }^{\circledR}$ ) fiber as adsorbent. For the optimization of the HS-SPME conditions, a $2^{2}$ trial planning with two quantitative variables (temperature and extraction time) has been carried out at two levels $\left(30\right.$ and $60{ }^{\circ} \mathrm{C} ; 3$ and 6 min, all in triplicate). Eight experiments were performed, and the statistical analysis was done by using the program Quality Tools: Statistics in Quality Science. ${ }^{26}$ Fresh leaves $(10 \mathrm{mg})$ of the plant and a magnetic bar were transferred to a $40 \mathrm{~mL}$ vial which was sealed with septum and a screw cap. The system was maintained at $60{ }^{\circ} \mathrm{C}$ (under water bath) and stirred at $120 \mathrm{rpm}$. Finally, the adsorbent fiber was introduced into the vial at $1 \mathrm{~cm}$ above the plant material. The volatile compounds were extracted by headspace during $3 \mathrm{~min}$. After this period, the fiber was removed and introduced into the GC-MS for desorption of the volatile constituents during 4 minutes at $250{ }^{\circ} \mathrm{C}$

\section{GC-MS analyses}

The volatile constituents extracted by hydrodistillation and HSSPME were analyzed on a QP-2010 gas chromatograph coupled to a mass spectrometer from Shimadzu ${ }^{\circledR}$, with a capillary DB-5 column ( $25 \mathrm{~m} \times 0.32 \mathrm{~mm} \times 0.5 \mu \mathrm{m}$ ) from $\mathrm{J} \& \mathrm{~W}$ Scientific ${ }^{\circledR}$. The analysis conditions were as follows: injector temperature $250^{\circ} \mathrm{C}$; GC oven temperature $35^{\circ} \mathrm{C}$ for $2 \mathrm{~min}$, from 35 to $195^{\circ} \mathrm{C}\left(20^{\circ} \mathrm{C} \mathrm{min}{ }^{-1}\right)$, from 195 to $220^{\circ} \mathrm{C}\left(10^{\circ} \mathrm{C} \mathrm{min}^{-1}\right)$, and from 220 to $280{ }^{\circ} \mathrm{C}\left(20^{\circ} \mathrm{C} \mathrm{min}{ }^{-1}\right)$; mode of injection 1:10 split; volumetric flow rate of the carrier gas (Helium) $0.59 \mathrm{~mL} \mathrm{~min}^{-1}$; detector temperature $250{ }^{\circ} \mathrm{C}$. Mass spectra were obtained by electron impact $(70 \mathrm{eV})$ in the range of $\mathrm{m} / \mathrm{z}, 18$ to 400 (intervals $0.5 \mathrm{~s}$ ). The volatile compounds were identified by analysis of the mass spectra obtained with those from mass spectral libraries (NIST ${ }^{27}$ and Adams ${ }^{28}$ ), and compared with the calculated retention indexes based on linear temperature-programmed gas chromatography ${ }^{29}$ with those from literature ${ }^{27} n$-Alkanes $\left(\mathrm{C}_{7}-\mathrm{C}_{30}\right.$, Sigma-Aldrich ${ }^{\circledR}$ ) were used as reference points in the calculation of linear retention indexes.

\section{Multivariate data analysis}

The GC-MS of the volatile constituents extracted by hydrodistillation (OELA) and by HS-SPME were subjected to Pearson's correlations matrix and HCA (hierarchical cluster analysis) analyses by using the free software R Project from R Foundation for Statistical Computing ${ }^{\circledR} .{ }^{26}$ The analyzed data correspond to the averages of injections in triplicate, and the matrix arrangement was made up of six lines (number of OELA and HS-SPME analyzed) and twenty columns (compounds identified with percentages $>2 \%$ ). For the HCA, Euclidean distance was used as the coefficient of dissimilarity. The grouping was done by the method of average association (Ward), with the option of automatic truncation in order to define the conglomerates and to obtain the dendrogram. ${ }^{30}$

\section{RESULTS AND DISCUSSION}

\section{Volatile composition of leaves from $L$. alba}

HS-SPME was used as alternative extraction method for discriminating three chemotypes of $L$. alba [myrcene-citral (chemotype I), limonene-citral (chemotype II) and carvone-limonene (chemotype III)] previously classified by Matos (1996) ${ }^{2}$ based on the composition of their essential oils extracted by hydrodistillation. The essential oils of the specimens were also obtained in order to compare their constituents with those extracted by HS-SPME (Table 1).

Twenty-one compounds were identified in the essential oil of chemotype I (myrcene-citral, OE-LAQI) of $L$. alba and the major compounds $[\beta$-myrcene $(25.81 \% \pm 1.14)$, neral $(19.82 \% \pm 1.18)$ and geranial $(25.76 \% \pm 0.10)]$ are in agreement with those previously reported. ${ }^{2}$ The same number of compounds was found in the volatile composition of this chemotype extracted by HS-SPME, CVF-LAQI (Table 1). Among these compounds, only twelve (50\%) are common to the essential oil. Although $\beta$-myrcene $(21.29 \% \pm 0.68)$ was also identified as a major constituent by HS-SPME, the percentages of neral $(4.20 \% \pm 0.15)$ and geranial $(3.89 \% \pm 0.01)$ are much lower than those found in the essential oil. In this case, the second major compound by HS-SPME was $(Z)$-hex-3-en-1-ol $(23.55 \% \pm 0.87)$ which, along with $(Z)$-hex-3-enal $(0.85 \% \pm 0.65),(E)$-hex-2-enal $(0.63 \% \pm 0.04)$, hexan-1-ol $(1.34 \% \pm 0.36)$, were not identified in the essential oil. Despite the low percentages of neral and geranial in the volatile composition by HS-SPME, it is relevant to mention the presence of the respective alcohols nerol $(0.98 \% \pm 0.30)$ and geraniol $(1.00 \% \pm 0.05)$ which were not identified in the essential oil. This result suggests that the extraction conditions (water and higher temperature) in the hydrodistillation process may contribute to the oxidation of nerol and geraniol to the corresponding aldehydes neral and geranial. Another example that corroborates this oxidative process is the presence of $\beta$-caryophylene $(2.04 \% \pm 0.17)$ and its derivative caryophylene oxide $(2.46 \% \pm 0.95)$ in the essential oil, but only $\beta$-caryophylene $(8.64 \% \pm 0.49)$ was found in the volatile composition by HS-SPME. The literature has also reported caryophylene oxide as an artefact from the oxidation of $\beta$-caryophylene. ${ }^{31}$

For the L. alba chemotype II (limonene-citral) the essential oil (OE-LAQII) presented eighteen compounds while HS-SPME extraction (CVF-LAQII) yielded twenty-six constituents (Table 1). In this case, only thirteen (44.83\%) are common to both methods of extraction. Concerning the major compounds, hydrodistillation and HS-SPME showed similar percentages of limonene $(13.17 \% \pm 0.24$ and $12.55 \% \pm 1.54$, respectively). Meanwhile, percentages of citral (neral and geranial) varied with the extraction method: neral $28.14 \%$ \pm 0.31 (hydrodistillation) and $12.84 \% \pm 1.04$ (HS-SPME); geranial $34.91 \pm 0.14$ (hydrodistillation) and $18.58 \% \pm 2.37$ (HS-SPME). 
Table 1. Chemical constituents identified on the leaves of $L$. alba chemotypes I, II and III by hydrodistillation and HS-SPME

\begin{tabular}{|c|c|c|c|c|c|c|c|c|}
\hline \multirow[b]{2}{*}{ Compound } & \multirow[b]{2}{*}{$\mathrm{RI}^{\mathrm{a}}$} & \multirow[b]{2}{*}{$\mathrm{RI}^{\mathrm{b}}$} & \multicolumn{4}{|c|}{ Essential oil (hydrodistillation) } & \multicolumn{2}{|c|}{ HS-SPME } \\
\hline & & & $\begin{array}{l}\text { OE-LAQI } \\
(\% \pm \mathrm{SD})\end{array}$ & $\begin{array}{l}\text { OE-LAQII } \\
(\% \pm \mathrm{SD})\end{array}$ & $\begin{array}{c}\text { OE-LAQIII } \\
(\% \pm \text { SD })\end{array}$ & $\begin{array}{c}\text { CVF-LAQI } \\
(\% \pm \mathrm{SD})\end{array}$ & $\begin{array}{c}\text { CVF-LAQII } \\
(\% \pm \mathrm{SD})\end{array}$ & $\begin{array}{c}\text { CVF-LAQIII } \\
(\% \pm \mathrm{SD})\end{array}$ \\
\hline (Z)-Hex-3-enal & 799 & 798 & - & - & - & $0.85 \pm 0.65$ & $0.42 \pm 0.07$ & $0.83 \pm 0.01$ \\
\hline 4-Hydroxy-4-methylpentan-2-one & 839 & 842 & $0.36 \pm 0.28$ & - & - & - & - & - \\
\hline (E)-Hex-2-enal & 850 & 855 & - & - & - & $0.63 \pm 0.04$ & $0.10 \pm 0.02$ & - \\
\hline (Z)-Hex-3-en-1-ol & 857 & 857 & - & - & - & $23.55 \pm 0.87$ & $4.07 \pm 0.12$ & - \\
\hline Hexan-1-ol & 867 & 869 & - & - & - & $1.34 \pm 0.36$ & $0.42 \pm 0.08$ & - \\
\hline$\alpha$-Thujene & 926 & 927 & $0.25 \pm 0.09$ & $0.29 \pm 0.06$ & $0.41 \pm 0.08$ & - & $0.26 \pm 0.03$ & $2.65 \pm 0.23$ \\
\hline Oct-1-en-3-ol & 979 & 980 & $0.31 \pm 0.14$ & - & - & $4.65 \pm 0.45$ & - & - \\
\hline$\beta$-Pinene & 980 & 982 & $0.28 \pm 0.16$ & $0.64 \pm 0.08$ & $5.12 \pm 0.68$ & - & $0.10 \pm 0.04$ & $0.61 \pm 0.21$ \\
\hline 6-Metil-hept-5-en-2-ona & 986 & 985 & $1.75 \pm 0.94$ & $1.07 \pm 0.26$ & - & - & - & - \\
\hline$\beta$-Myrcene & 991 & 992 & $25.81 \pm 1.14$ & $0.32 \pm 0.06$ & $0.60 \pm 0.07$ & $21.29 \pm 0.68$ & - & - \\
\hline (Z)-Hex-3-enyl acetate & 1004 & 1005 & - & - & - & $3.13 \pm 0.43$ & $1.08 \pm 0.07$ & - \\
\hline$\alpha$-Terpinene & 1025 & 1025 & - & - & $0.26 \pm 0.01$ & - & - & - \\
\hline$p$-Cymene & 1024 & 1027 & $7.20 \pm 0.11$ & $2.14 \pm 0.06$ & $0.35 \pm 0.09$ & $1.67 \pm 0.26$ & $2.98 \pm 0.53$ & - \\
\hline D-Limonene & 1037 & 1038 & - & $13.17 \pm 0.24$ & $20.06 \pm 1.83$ & - & $12.55 \pm 1.54$ & $13.21 \pm 3.22$ \\
\hline$(E)-\beta$-Ocimene & 1050 & 1051 & $0.81 \pm 0.04$ & $0.43 \pm 0.03$ & $0.42 \pm 0.02$ & $0.68 \pm 0.12$ & $0.62 \pm 0.09$ & $0.45 \pm 0.01$ \\
\hline$\gamma$-Terpinene & 1066 & 1067 & $4.19 \pm 0.18$ & $4.16 \pm 0.31$ & $2.37 \pm 0.01$ & $4,02 \pm 0.51$ & $6.11 \pm 1.09$ & $2.16 \pm 0.04$ \\
\hline cis-Sabinene hydrate & 1082 & 1078 & - & - & $1.01 \pm 0.06$ & - & $0.42 \pm 0.07$ & $1.81 \pm 0.14$ \\
\hline$\beta$-Linalool & 1099 & 1102 & $0.95 \pm 0.06$ & $0.84 \pm 0.08$ & $0.90 \pm 0.05$ & $0.73 \pm 0.18$ & $1.24 \pm 0.09$ & - \\
\hline trans-Sabinene hydrate & 1098 & 1110 & - & - & $0.66 \pm 0.03$ & - & - & $0.73 \pm 0.26$ \\
\hline NI & - & 1149 & $0.24 \pm 0.04$ & $0.49 \pm 0.01$ & - & - & - & - \\
\hline$\beta$-Citronelal & 1154 & 1157 & - & $0.30 \pm 0.02$ & - & - & - & - \\
\hline NI & - & 1163 & $0.23 \pm 0.04$ & - & - & - & - & - \\
\hline (Z)-Isocitral & 1165 & 1168 & $0.68 \pm 0.04$ & $0.95 \pm 0.04$ & - & - & $0.56 \pm 0.10$ & - \\
\hline NI & - & 1185 & $1.04 \pm 0.09$ & $1.65 \pm 0.04$ & - & - & - & - \\
\hline NI & - & 1186 & - & - & - & - & $1.39 \pm 0.02$ & - \\
\hline Terpinen-4-ol & 1193 & 1195 & - & - & $0.92 \pm 0.09$ & - & - & - \\
\hline cis-Dihydrocarvone & 1207 & 1214 & - & - & - & - & - & $1.36 \pm 0.04$ \\
\hline trans-Dihydrocarvone & 1218 & 1224 & - & - & - & - & - & $1.27 \pm 0.10$ \\
\hline$\beta$-Citronellol & 1228 & 1229 & - & $0.68 \pm 0.02$ & - & - & $0.62 \pm 0.11$ & - \\
\hline NI & - & 1231 & - & - & - & $0.34 \pm 0.04$ & - & - \\
\hline Nerol & 1230 & 1234 & - & $2.23 \pm 0.09$ & - & $0.98 \pm 0.30$ & $10.09 \pm 0.41$ & - \\
\hline Neral & 1248 & 1249 & $19.82 \pm 1.18$ & $28.14 \pm 0.30$ & - & $4.20 \pm 0.14$ & $12.84 \pm 1.04$ & - \\
\hline Geraniol & 1254 & 1257 & - & $1.00 \pm 0.05$ & - & $1.00 \pm 0.05$ & $11.41 \pm 0.62$ & - \\
\hline Carvone & 1265 & 1261 & - & - & $58.99 \pm 1.89$ & - & - & $64.76 \pm 2.32$ \\
\hline Geranial & 1271 & 1277 & $25.76 \pm 0.10$ & $34.91 \pm 0.14$ & - & $3.89 \pm 0.01$ & $18.58 \pm 2.37$ & - \\
\hline$\alpha$-Copaene & 1401 & 1405 & $1.47 \pm 0.02$ & - & - & $7.28 \pm 0.36$ & - & - \\
\hline$\beta$-Elemene & 1409 & 1415 & $0.95 \pm 0.15$ & - & - & $1.69 \pm 0.07$ & - & - \\
\hline NI & - & 1416 & - & - & $0.70 \pm 0.07$ & - & - & - \\
\hline 6-epi- $\alpha$-Cubebene & 1412 & 1418 & - & - & - & - & $0.59 \pm 0.41$ & - \\
\hline$\beta$-Bourbonene & 1417 & 1419 & - & - & - & - & - & $1.69 \pm 0.21$ \\
\hline$\beta$-Caryophyllene & 1451 & 1457 & $2.04 \pm 0.16$ & - & - & $8.64 \pm 0.49$ & $1.59 \pm 0.31$ & $0.47 \pm 0.01$ \\
\hline cis-Muurola-4(14),5-diene & 1462 & 1465 & - & - & $2.57 \pm 0.24$ & - & $0.58 \pm 0.09$ & $0.36 \pm 0.13$ \\
\hline$\alpha$-Humulene & 1489 & 1492 & $0.16 \pm 0.04$ & - & - & - & - & - \\
\hline NI & - & 1502 & - & - & - & $0.24 \pm 0.09$ & - & - \\
\hline$\alpha$-Curcumene & 1490 & 1502 & - & - & - & - & $0.69 \pm 0.05$ & - \\
\hline NI & - & 1507 & - & - & - & $0.40 \pm 0.05$ & $0.11 \pm 0.02$ & - \\
\hline$\alpha$-Zingiberene & 1505 & 1513 & - & - & - & - & $0.72 \pm 0.01$ & - \\
\hline Germacrene D & 1510 & 1517 & $0.80 \pm 0.27$ & $1.56 \pm 0.13$ & $0.51 \pm 0.06$ & - & - & $0.16 \pm 0.14$ \\
\hline$\gamma$-Cadinene & 1515 & 1519 & - & - & - & $3.91 \pm 1.08$ & $5.31 \pm 0.04$ & $4.57 \pm 0.33$ \\
\hline$\delta$-Cadinene & 1548 & 1551 & $0.33 \pm 0.26$ & - & - & $0.76 \pm 0.09$ & - & $0.57 \pm 0.16$ \\
\hline$\beta$-Elemol & 1570 & 1576 & $2.09 \pm 0.23$ & $3.51 \pm 0.09$ & $3.71 \pm 0,11$ & $0.31 \pm 0.07$ & $1.15 \pm 0.02$ & - \\
\hline Guaiol & 1595 & 1600 & - & - & $0.20 \pm 0.12$ & - & - & - \\
\hline Caryophyllene oxide & 1619 & 1628 & $2.46 \pm 0.95$ & - & - & - & - & - \\
\hline Total & & & 99.98 & 99.39 & 99.76 & 96.18 & 97.23 & 97.66 \\
\hline
\end{tabular}

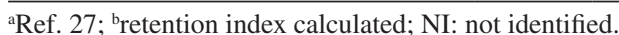


Table 2. Pearson's correlation matrix for the volatile chemical composition of L. alba (chemotypes I, II and III) using hydrodistillation (OE-LAQI-III) and HS-SPME (CVF-LAQI-III)

\begin{tabular}{|c|c|c|c|c|c|c|}
\hline Chemotypes & CVF-LAQI & CVF-LAQII & CVF-LAQIII & OE-LAQI & OE-LAQII & OE-LAQIII \\
\hline CVF-LAQI & 1.00 & -0.14 & -0.20 & 0.36 & -0.10 & -0.22 \\
\hline CVF-LAQII & -0.14 & 1.00 & -0.13 & 0.42 & 0.81 & -0.09 \\
\hline CVF-LAQIII & -0.20 & -0.13 & 1.00 & -0.17 & -0.08 & 0.98 \\
\hline OE-LAQI & 0.36 & 0.42 & -0.17 & 1.00 & 0.69 & -0.17 \\
\hline OE-LAQII & -0.10 & 0.81 & -0.08 & 0.69 & 1.00 & -0.05 \\
\hline OE-LAQIII & -0.22 & -0.09 & 0.98 & -0.17 & -0.05 & 1.00 \\
\hline
\end{tabular}

Bold numbers are significant considering $\alpha=5 \%$.

This chemotype produced the corresponding alcohols nerol (10.09\% $\pm 0.41)$ and geraniol $(11.41 \% \pm 0.62)$ by HS-SPME in higher percentage than those found by hydrodistillation [nerol $(2.23 \% \pm$ $0.09)$ and geraniol $(1.00 \% \pm 0.05)]$. Again, this result corroborates the hypothesis of neral and geranial being artefacts formed during the hydrodistillation process. It is noteworthy that chemotype II produced nerol and geraniol in higher yields than chemotype I. As for chemotype I, HS-SPME has also allowed the identification of (Z)-hex-3-en-1-ol (4.07\% \pm 0.12$),(Z)$-hex-3-enal $(0.42 \% \pm 0.07),(E)$ hex-2-enal $(0.10 \% \pm 0.02)$, hexan-1-ol $(0.42 \% \pm 0.08)$, all compounds lacking in the essential oil.

All volatile compounds extracted from leaves of $L$ alba chemotype III (limonene-carvone) by hydrodistillation (OE-LAQIII) and HS-SPME (CVF-LAQIII) are presented in Table 1. The numbers of identified compounds were seventeen for both hydrodistillation and HS-SPME. However, only ten compounds (58.82\%) are common to both methods of extraction. The volatile profile of the major compounds extracted by hydrodistillation and HS-SPME was very similar. Limonene was found in $20.06 \% \pm 1.83$ (hydrodistillation) and $13.21 \% \pm 3.22$ (HS-SPME), while carvone was identified in $58.99 \%$ \pm 1.89 (hydrodistillation) and $64.76 \% \pm 2.32$ (HS-SPME). Unlike what was observed in the chemical composition of chemotypes I and II, only $(Z)$-hex-3-en-1-ol $(0.83 \% \pm 0.01)$ was identified as low molecular weight compound in chemotype III.

Although limonene-carvone was identified as chemomarkers for L. alba chemotype III using the two different methods of extraction, some relevant variations concerning the major compounds were found for chemotypes I (myrcene-citral) and II (limonene-citral). Chemotype I produced low percentages of citral (neral and geranial) by HS-SPME, and the major compounds were myrcene and $(Z)$ hex-3-en-1-ol. For chemotype II, citral (neral and geranial) and the corresponding alcohols (nerol and geraniol) similar percentages of limonene were found. Schossler et al. ${ }^{24}$ have pointed out HS-SPME as a mild method for extracting volatile compounds from plants as it avoids all chemical transformations that may occur during the hydrodistillation process. The detection of oxygenated VOCs with low molar mass ( 6 carbon atoms) in the analyzes using HS-SPME can be explained by the use of fiber PDMS/DVB since this fiber presents porosity and adsorptive capacity for analytes having molecular structures with 6-15 carbon atoms. In the hydrodistillation process, the more volatile compounds and those with high affinity with the aqueous phase are lost in gas phase and hydrolate, respectively. ${ }^{24}$ Thus, the results presented in this manuscript corroborate the importance of the extraction method on the discrimination of L. alba chemotypes, and suggest the use of HS-SPME as an alternative tool on the identification of volatile compounds from plants.

\section{Multivariate data analysis}

Pearson's correlations was performed by considering the twenty volatile compounds with percentages $>2 \%$ identified for all chemotypes by hydrodistillation (OE-LAQ) and HS-SPME (CVF-LAQ), and the corresponding matrix is displayed in Table 2. Significant correlations were observed between the extractions methods for each chemotype. The strongest correlation was found between CVF-LAQII and OE-LAQII, followed by CVF-LAQIII and OE-LAQIII.

Through the analysis of the essential oils (hydrodistillation method) it is possible to observe a significant correlation between chemotypes I and II ( $\mathrm{p}=0.000)$ meaning that this method of extraction is not suitable for distinguishing them. Meanwhile, HS-SPME showed to be a more suitable technique for this purpose, since no significant correlations were observed between the chemical compositions of the three chemotypes.

Figure 1 shows the dendrogram of HCA for the volatile chemical composition of L. alba (chemotypes I, II and III) using hydrodistillation and HS-SPME. Although the three chemotype were well distinguished by HS-SPME, the essential oils from chemotype I and II are in the same hierarchic level and do not allow their differentiation. The volatile composition of chemotype III obtained by hydrodistillation and HS-SPME are in the same hierarchy level, meaning that the extraction methods provide similar chemical composition. In summary, the exploratory data analysis showed that the volatile chemical composition of the three chemotypes of $L$. alba is better differentiated when HS-SPME is used as extraction method.

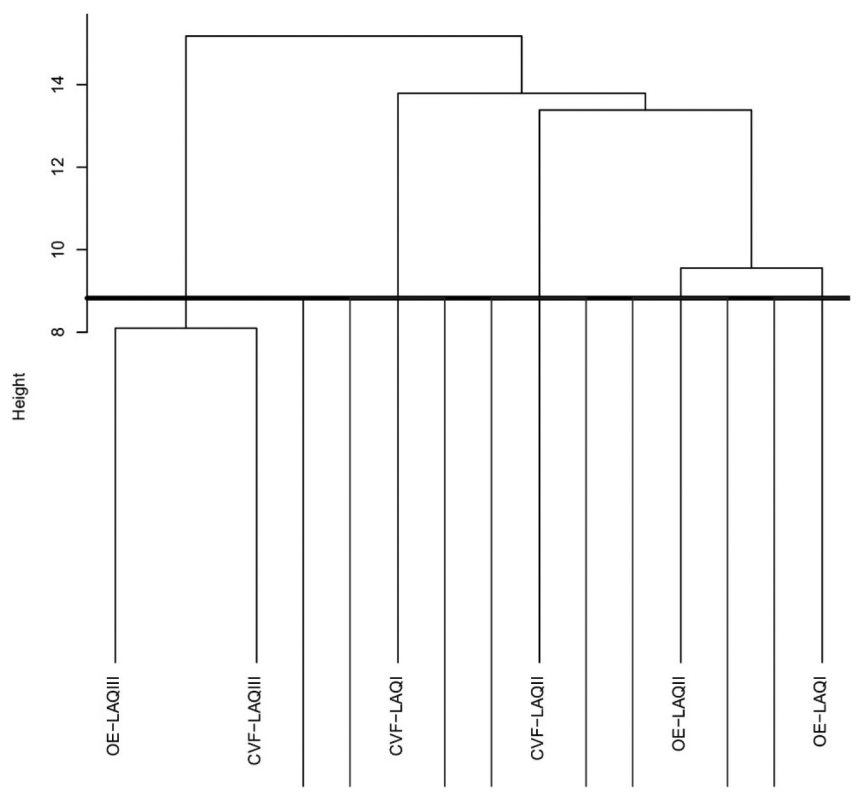

Figure 1. Dendrogram of HCA of the volatile chemical composition of $L$. alba (chemotypes I, II and III) using hydrodistillation (OE-LAQI-III) and HS-SPME (CVF-LAQI-III) 


\section{CONCLUSION}

HS-SPME was used as alternative tool to distinguish three chemotypes of $L$. alba from the Northeast region of Brazil, and compared with the traditional hydrodistillation method. It was demonstrated that HS-SPME is more efficient for this purpose since, besides better discriminating the chemotypes, it also avoids artefacts produced during hydrodistillation. Additionally, it was demonstrated that the chemomarkers for each chemotype varies with the extraction method

\section{SUPPLEMENTARY MATERIAL}

Figures 1S-6S with chromatograms of GC-MS are available at http://quimicanova.sbq.org.br, as a pdf file, with free access.

\section{ACKNOWLEDGEMENT}

The authors thank the Brazilian funding agencies CNPq (Process 405001/2013-4) and CAPES for the financial support. M. C. F. de Oliveira thanks CNPq for the research grant (Process 303365/2014-5).

\section{REFERENCES}

1. Hennebelle, T.; Sahpaz, S.; Joseph, H.; Bailleul, F.; J. Ethnopharmacol. 2008, 116, 211.

2. Matos, F. J. A.; Rev. Bras. Farm. 1996, 77, 65; Matos, F. J. A.; Rev. Bras. Farm. 1996, 77, 137; Matos, F. J. A.; Machado, M. I. L.; Craveiro, A. A.; Alencar, J. W.; J. Essent. Oil Res. 1996, 8, 695.

3. Biasi, L. A.; Costa, G.; Cienc. Rural 2003, 33, 455.

4. Di Stasi, L. C.; Oliveira, G. P.; Carvalhaes, M. A.; Queiroz-Júnior, M.; Tien, O. S.; Kakinami, S. H.; Reis, M. S.; Fitoterapia 2002, 73, 69.

5. Mattos, S. H. Em Série BNB Ciência e Tecnologia 2; Mattos, S. H; Innecco, R.; Marco, C. A.; Araújo, A. V., eds; Banco do Nordeste do Brasil: Fortaleza, 2007, cap. 1.

6. Shukla, R.; Kumar, A.; Singh, P.; Dubey, N. K.; Int. J. Food Microbiol. 2009, 135, 165.

7. Niculau, E. S.; Alves, P. B.; Nogueira, P. C. L.; Moraes, V. R. S.; Matos, A. P.; Bernardo, A. R.; Volante, A. C.; Fernandes, J. B.; da Silva, M. F. G. F.; Corrêa, A. G.; Blank, A. F.; Silva, A. C; Ribeiro, L. P.; Quim. Nova 2013, 36, 1391.

8. Blanco, M. A; Colareda, G. A.; van-Baren, C.; Bandoni, A. L.; Ringuelet, J.; Consolini, A. E.; J. Ethnopharmacol. 2013, 149, 803.

9. Haldar, S.; Kar, B.; Dolai, N.; Kumar, R. B. S.; Behera, B.; Haldar, P. K.; Asia Pac. J. Trop. Dis. 2012, 2, S667.

10. Mesa-Arango, A. C.; Betancur-Galvis, L.; Montiel, J.; Bueno, J. G.; Baena, A.; Durán, D. C.; Martínez, J. R.; Stashenko, E. E.; J. Essent. Oil Res. 2010, 22, 568.
11. Pascual, M. E.; Slowing, K.; Carretero, E.; Mata, D. S.; Villar, A.; J. Ethnopharmacol. 2001, 76, 201; Gomes, S. V. F.; Nogueira, P. C. L.; Moraes, V. R. S.; Eclet. Quim. 2011, 36, 64.

12. Barbosa, F. G.; Lima, M. A. S.; Braz-Filho, R.; Silveira, E. R.; Biochem. Syst. Ecol. 2006, 34, 819; Barbosa, F. G.; Lima, M. A. S.; Braz-Filho, R.; Silveira, E. R.; Magn. Reson. Chem. 2005, 43, 334.

13. Hennebelle, T.; Sahpaz, S.; Dermont, C.; Joseph, H.; Bailleul, F.; Chem. Biodivers. 2006, 3, 1116.

14. Keefover-Ring, K.; Thompson, J. D.; Linhart, Y. B.; Flavour Fragr. J. 2009, 24, 117.

15. Tavares, E. S.; Julião, L. S.; Lopes, D.; Bizzo, H. R.; Lage, C. L. S.; Leitão, S. G.; Rev. Bras. Farm. 2005, 15, 1.

16. Silva, N. A.; Oliveira, F. F.; Costa, L. C. B.; Bizzo, H. R.; Oliveira, R. A.; Rev. Bras. Plantas Med. 2006, 8, 52.

17. Dellacassa, E.; Soler, E.; Menendez, P.; Moya, P.; Flavour Fragr. J. 1990, 5, 107.

18. Pino, J. A.; Ortega, A.; Rosado, A.; J. Essent. Oil Res. 1996, 8, 445.

19. Zoghbi, M. das G. B.; Andrade, E. H. A.; 1 Santos, A. S.; Silva, M. H. L.; Maia, J. G. S.; Flavour Fragr. J. 1998, 13, 47.

20. De Barros, F. M. C.; Zambarda, E. de O.; Heinzmann, B. M.; Mallmann, C. A.; Quim. Nova 2009, 32, 861.

21. Castro, D. M.; Ming, L. C.; Marques, M. O. M.; Rev. Bras. Plantas Med. 2002, 4, 75 .

22. Jannuzzi, H.; Mattos, J. K. A.; Vieira, R. F.; Silva, D. B.; Bizzo, H. R.; Gracindo, L. A. M.; Hortic. Bras. 2010, 28, 412.

23. Sabino, J. F. P.; Reyes, M. M.; Barrera, C. D. F.; da Silva, A. J. R.; Quim. Nova 2012, 35, 97.

24. Schossler, P.; Schneider, G. L.; Wunsch, D.; Soaresb, G. L. G.; Zini, C. A.; J. Braz. Chem. Soc. 2009, 20, 277; Benyelles, B.; Allali, H.; Dib, M. E. A.; Djabou, N.; Tabti, B.; Costa, J.; J. Saudi Chem. Soc. 2014, 18, 972; Demyttenaere, J. C. R.; Morina, R. M.; Kimpe, N. D.; Sandra, P.; J. Chromatogr. A 2004, 1027, 147.

25. Charles, D. J.; Simon, J. E.; J. Am. Soc. Hortic. Sci. 1990, 115, 458.

26. R Development Core Team (2014); R: A language and environment for statistical computing; R Foundation for Statistical Computing, Vienna, Austria, available at http://www.R-project.org.

27. http://webbook.nist.gov/chemistry/, acessada em junho de 2015.

28. Adams, R. P.; Identification of Volatile Oil Components by Gas Chromatography/Mass Spectroscopy, $4^{\text {th }}$ ed., Allured Publishing Corporation: Carol Stream, 2007.

29. Van den Dool, H.; Kratz, P. D.; J. Chromatogr. 1963, 11, 463.

30. Hair Jr, J. F.; Anderson, R. E.; Tatham, R. L.; Black, W. C.; Análise Multivariada de Dados, $5^{\mathrm{a}}$ ed., Porto Alegre: Bookman, 2005.

31. Sköld, M.; Karlberg, A. T.; Matura, M.; Börje, A.; Food Chem. Toxicol. 2006, 44, 538. 